\title{
How gender and child sensitive was the relief received after the tsunami?
}

\author{
Manouri P Senanayake ${ }^{1}$, Chinthana Ranawaka ${ }^{2}$, Manisha Fernanado ${ }^{3}$
}

Sri Lanka Journal of Child Health, 2011; 40: 9-10

(Key words: Tsunami; relief; gender; child sensitive)

The status of women has a direct bearing on the condition of children. Countries where child mortality and morbidity are high rate low on how they treat women ${ }^{1}$. Disaster affected populations are also said to reflect a gender bias and such inequalities were reported following the tsunami of 2004, from Indonesia and India ${ }^{2,3}$. We assessed the gender impact of the post disaster health response and recovery process in a severely tsunami affected community in southern Sri Lanka.

\section{Objectives}

1. To collect gender and age disaggregated data of an affected community

2. To assess whether health and other assistance strategies had addressed gender issues and been child friendly

3. To identify whether gender had played a role in the recovery process

\section{Setting}

Seenigama, Southern Province Sri Lanka

\section{Method}

Pre and post disaster population structures were analysed. Focus group discussions with families attending a polyclinic set up in the immediate aftermath of the disaster and interview of key informants were utilized and the recovery process was assessed through a household survey carried out 14 months after the disaster and an interviewer

\footnotetext{
${ }_{1}^{1}$ Professor in Paediatrics, Department of Paediatrics, Faculty of Medicine, Colombo, ${ }^{2}$ Pre-intern Medical Officer, ${ }^{3}$ Volunteer General Practitioner, Australian Youth Ambassador Programme
}

(Received on 22 April 2010. Accepted on 20 May 2010) administered questionnaire was used to record responses.

\section{Results}

The village of Seenigama comprised a pre-disaster total population of 1448 persons. Recorded deaths totaled 120 with a profile of 60 adult women, 39 adult men and 21 children $^{4}$. Almost all dwellings were damaged. Fourteen months after the disaster 412 families continued to live in this village. Majority of households attended a poly-clinic that was initiated by a local non-governmental organization and the Sri Lanka College of Paediatricians and clinic records were available for over 400 under 18 year olds.

One hundred and twenty five randomly selected women consented to share their experiences of the relief received while in makeshift refugee camps and during the process of rebuilding their lives at home. Thirty nine respondents were from female headed households.

Relief received in the immediate post-disaster period was described by $88 \%$ as "did not have to compete with men to receive food" and by $68 \%$ as "food and other provisions were distributed separately to women and children". However, 76\% said they did not have access to women relief workers for discussion of their needs. "Separate bathing facilities" were not available (58\%) and "access to sanitary items" was limited or absent (45\%). Services for reproductive health i.e. family planning had been available to $45 \%$ of the women. Medical services in the camp setting were freely available for children although physical needs of children were inadequate $(88 \%)$.

Privacy was inadequate when sleeping, dressing and toileting for $20 \%, 16 \%$ and $16 \%$ of women and $40 \%$ said they had lived in fear of their personal security.

Seven of 39 widows said being a woman made it harder for obtaining relief during the recovery period. 
The burden of household chores and child care were reasons for these difficulties. However, 32 (82\%) of this 39 said they had not experienced difficulties due to being a woman and had had access to aid agencies, help from kinship groups and financial support with no gender bias.

\section{Discussion}

Our survey in a tsunami-affected community found a gender disparity in victimization with a significantly higher mortality among women. Physical differences in the struggle for survival may have been the cause and this disproportionate disadvantage may have biological, social and cultural characteristics too.

In the immediate aftermath the needs of women had been attended to although inadequacies centered around reproductive and psychological health issues. However, during the recovery phase we found women to be rebuilding their lives without feeling vulnerable based on gender. Our survey did not address long-term implications of demographic imbalance such as pressures on women to remarry, or if female headed households faced greater economic burdens.

Although a differential gender impact was not widespread in the recovery phase in the village we surveyed in southern Sri Lanka we recommend greater attention to issues of privacy and psychological support by post-event health responders as well as a more gender centered and child friendly approach during the recovery phase.

\section{Acknowledgements}

We thank Mr Kushil Gunasekera and the Foundation of Goodness Seenigama and Council of the Sri Lanka College of Paediatricans 2005 for their untiring efforts and assistance.

\section{References}

1. State of the World's Children Report. 2006 : UNICEF

2. Aglionby J. Four times as many women died in tsunami. The Guardian, 2005 March 26

3. Fitzpatrick D. 2008 Women's right to land and housing in Aceh Indonesia. In: Aceh Working Paper No 3. Asia Research Institute, Singapore

4. Oxfam Briefing Note: The tsunami's impact on women Oxfam International, March 2005 